Weronika Urbanik-Pęk (D) Uniwersytet Pedagogicznyw Krakowie weronika.urbanik-pek@up.krakow.pl

\title{
El Análisis Melódico del Habla Un método para abordar el análisis de la entonación del español hablado por polacos
}

\section{Resumen:}

El presente artículo hace una presentación de un método innovador para analizar la entonación del español. Este modelo desarrollado en el Laboratorio de Fonética Aplicada de Barcelona permite visualizar la línea melódica de cualquier contorno y compararla con los patrones melódicos existentes en castellano.

En el texto, tras una breve introducción sobre la entonación y una descripción de los precedentes teóricos de la entonación, se presentan los patrones melódicos del español. Después, de manera más detallada se describe el método Análisis Melódico del Habla (AMH), sus rasgos característicos y la metodología de análisis que propone. Dicho método, aplicado a analizar diversas lenguas y, también, interlenguas, como por ejemplo las investigaciones sobre el español hablado por aprendientes de una lengua extranjera, se ha encontrado con mucho interés y son cada vez más los investigadores que desean seguirlo para ofrecer luego a sus alumnos una información precisa y clara para trabajar la entonación.

Dedicar más tiempo en la enseñanza de ELE a la pronunciación adecuada y emisión correcta de los enunciados es una necesidad vigente ya que tener un alto dominio de lengua implica no solo saber el vocabulario y la gramática, sino que también aplicar la melodía correcta a nuestra habla para evitar los malentendidos en la comunicación. Esperamos que el presente texto acerque el conocimiento de una nueva e interesante herramienta y despierte más interés por la entonación de ELE en el ámbito polaco. 
Palabras clave: Análisis Melódico del Habla (AMH), entonación, interlengua, español hablado por polacos, fonética

\begin{abstract}
:
The Melodic Analysis of Speech. A Method to Approach the Analysis of the Intonation of Spanish Spoken by Poles

This article pretends to make a brief presentation of an innovative methodology to analyze the intonation of Spanish. This model, which was developed in the Laboratory of Applied Phonetics of Barcelona, allows to visualize the melodic line of any contour and compare it with the melodic patterns existing in Spanish. After a brief introduction about the intonation, we mention the theoretical precedents of intonation and we present the melodic patterns of Spanish. Then, we present in more details the Melodic Analysis of Speech, showing its characteristic features and describing the analysis methodology it proposes. This method is applied to analyze several interlanguages of Spanish spoken by students from different nations. More and more professors and researchers are following this method to offer their students a precise and clear tool to work with the intonation. Teaching the proper pronunciation and the correct issuance of the sentences in the FL classes is a current necessity. A high command of the language implies not only knowing the vocabulary and grammar but also applying the correct melody to our speech which can help us to avoid misunderstandings in communication. We hope that this text brings the knowledge of a new and interesting method and arouses more interest in the intonation of Spanish spoken by Poles.
\end{abstract}

Keywords: Melodic Analysis of Speech (MAS), intonation, interlanguage, Spanish spoken by Poles, Phonetics

\title{
1. Introducción
}

De todos los elementos suprasegmentales de la fonética española, la entonación suele ser la cuestión menos estudiada en las clases de ELE en Polonia. Hay varias razones que provocan la falta de interés por la entonación. Unos profesores no la trabajan porque no se sienten expertos en este ámbito; para otros, su acento no es el más apropiado para ponerlo como ejemplo para sus discípulos; y los demás mencionan que no hay métodos ni materiales para enseñarla. Por otro lado, se suele considerar el español como una lengua cuyos sonidos son 
fáciles de emitir de manera correcta, lo que no obliga a practicar ni a esforzarse mucho. Estamos de acuerdo con que para un estudiante polaco la articulación de los sonidos españoles no es un gran reto. No obstante, consideramos que aunque un alumno polaco es capaz de dominar bien la gramática y el vocabulario, puede presentar dificultades comunicativas provocadas por el uso de una entonación inadecuada en diversos contextos.

Como hemos mencionado, muchos dicen que las ideas para trabajar la entonación son escasas, por lo tanto, para intentar salvar la brecha existente en los estudios dedicados a la entonación, en el presente artículo, queremos hacer una presentación bastante detallada de un método poco conocido en el ámbito universitario polaco. Nuestro objetivo es mostrar una idea nueva, aplicada ya a diversas lenguas e interlenguas, y despertar más interés por el estudio de la entonación del español, en nuestro caso, la entonación del español hablado por polacos. Esperamos que la descripción del Análisis Melódico del Habla empuje a los investigadores o a los estudiantes a trabajar más con la melodía del castellano, lo cual podrá traducirse, en un futuro, en la publicación de estudios que versen sobre la entonación.

\subsection{La entonación}

Numerosos lingüistas expresan la opinión de que la entonación es un conjunto de melodías concretas y definidas en ciertos contextos que se utilizan para expresar la intención comunicativa del hablante. Es como una herramienta para el emisor que le permite manifestar su actitud subjetiva frente a lo que está diciendo y, al mismo tiempo, una pauta para el destinatario que le facilita la reacción respecto a lo escuchado. A menudo es un elemento crucial para la comprensión adecuada del enunciado.

Hace años Navarro Tomás decía que:

Pronunciar el español con entonación inglesa o el inglés con entonación española es en suma una impropiedad semejante a la que se comete al hablar cualquiera de estas lenguas bajo la influencia de los sonidos o gramática de la otra (Navarro Tomás, 1944: 9). 
Esta cita de un lingüista reconocido e influyente en el estudio de la entonación española muestra la importancia de la entonación en el proceso de aprendizaje de una lengua. Este mismo autor mencionaba que, aunque a mucha gente, a la hora de estudiar una lengua extranjera, les parece obvio acercarse y ejercitarse en la práctica de nuevas formas gramaticales o la articulación adecuada de los fonemas y alófonos, les cuesta mucho o incluso forma una barrera insuperable imitar la melodía del habla propia de una lengua extranjera. Sabemos, hoy en día, que la entonación a menudo es un elemento clave para la comprensión del sentido de una frase en un contexto determinado.

En la actualidad se suele opinar que la entonación no solo es un fenómeno de carácter lingüístico, sino que desempeña también un papel sumamente importante en el aspecto expresivo de una conversación. Quilis (1981: 392) distinguía tres niveles fundamentales en los que podía actuar la entonación: el nivel lingüístico con su función distintiva, el nivel sociolingüístico cuyo objetivo era aportar información sobre el hablante y permitir identificarlo, y el nivel expresivo que transmitía el estado emocional del hablante.

En las definiciones incluidas en diccionarios o libros de fonética se señala, con frecuencia, que la entonación, como uno de los elementos prosódicos, está constituida por cuatro características fonéticas de los sonidos del habla: el tono, la intensidad, el timbre y la duración (así afirman, por ejemplo, Martínez Celdrán y Fernández Planas (2007)).

Cantero (2002: 15) la define como el fenómeno lingüístico constituido por las variaciones de tono relevantes en el discurso oral. Subraya además que es el principal elemento cohesionador del habla que cumple distintas funciones lingüísticas y expresivas en la comunicación oral. Añade que es como la interpretación lingüística (fonológica) de la melodía del habla: "la melodía es el fenómeno fonético que interpretamos fonológicamente como entonación” (Cantero, 2019: 489).

La historia de la entonación muestra que la investigación de la entonación puede realizarse según dos opciones. Se puede hacer mediante el análisis de configuraciones examinando la curva entonativa por las configuraciones o contornos significativos que la constituyen, o mediante el análisis de niveles optando por un estudio segmental por 
niveles tonales, acentos y junturas (Cantero, 2002: 32-33). El último permite segmentar la entonación en unidades discretas y oponibles entre sí, semejantes a los fonemas. El examen de configuraciones trata a la entonación como un fenómeno suprasegmental que constituye unidades mayores (llamadas configuraciones) que contrastan gradualmente.

A lo largo del siglo XX, dentro de esta división binaria del estudio de la entonación, surgieron muchas aportaciones teóricas sobre la entonación y sus aplicaciones a las tecnologías del habla que ofrecieron visiones discrepantes de este estudio. Las escuelas británica y americana de principios del siglo XX eran pioneras en ofrecer los modelos lingüísticos de la entonación analizando la prosodia del inglés. Tras estas dos que han tenido varios seguidores en distintas lenguas, también en español, aparecieron otras metodologías para trabajar la entonación como el modelo IPO (de la escuela holandesa), el modelo de Aix-en-Provence, y el modelo métrico y autosegmental y su sistema de etiquetaje ToBI (Tones and Break Indices), entre otros ${ }^{1}$.

\section{La entonación del español y sus patrones melódicos}

En el párrafo anterior acabamos de mencionar la escuela española del análisis de la entonación. En el presente apartado, ampliando un poco el tema y fijándonos en especial en la entonación del español, facilitaremos más datos sobre los estudios de la entonación realizados por varios investigadores españoles.

En la primera mitad del siglo XX Navarro Tomás empieza a crear los fundamentos del análisis de la entonación española. Su manual del año 1944 sigue de cerca el modelo británico y tiene como objetivo la enseñanza de la pronunciación española. A partir de los fines didácticos, este manual aporta mucha información teórica sobre el modelo por el que opta. Navarro Tomás discierne claramente los elementos prosódicos: el acento y la entonación, y -sirviéndose de los instrumentos de los que disponía- los mide de la manera más detallada

1 Para más detalles relativos a estos métodos, véase Prieto (2003). 
posible. A lo largo de su investigación enumera tres aspectos cruciales: la constitución fonológica de la frase, el análisis de la unidad melódica y la tipología entonativa. Su manual, un trabajo muy completo con un corpus amplio y versátil, ha servido como punto de partida para muchos investigadores posteriores.

Sin embargo, no todos los fonetistas partieron de lo que ha propuesto Navarro Tomás y algunos optaron por seguir otros métodos, como el análisis por niveles, el modelo IPO o el método métricoautosegmental, entre otros.

Hacia la mitad del siglo XX, Bowen (1956) y Silva-Fuenzalida (1957) proponen el análisis por niveles del español, acercándose en sus publicaciones a la escuela americana. Unas décadas después Quilis (1981) intenta relacionar sus propuestas con el análisis por configuraciones y analiza la entonación mezclando estos dos métodos.

En los años 90, gracias al desarrollo tecnológico y fácil acceso a numerosas herramientas para trabajar con la entonación, surgen muchos trabajos en este ámbito. Cabrera-Abreu (1991) opta por el análisis por configuraciones, según la tradición británica. Al mismo tiempo, Garrido (1996) aplica en su investigación el sistema de estilización de la escuela holandesa. En 1996 García Riverón propone combinar la doctrina de Navarro Tomás con los métodos de la lingüística soviética y describe de manera muy precisa el español de Cuba.

A finales del siglo XX, Sosa (1999), analizando el español de América, sigue el análisis métrico y autosegmental y según un enfoque generativo constituye el punto de referencia para los estudios de la entonación del español. A continuación, varios autores intentan aplicar su metodología a sus investigaciones dedicadas a la entonación de otras lenguas (Elordieta (1999) la del euskera, Prieto (2001) la del catalán). Asimismo, cabe mencionar la propuesta de Hidalgo (1997) que pretende describir la entonación del discurso oral en español: es el primer intento de describir de modo empírico la entonación del discurso con el objeto de definir las unidades demarcativas del habla.

Este breve repaso de las propuestas del análisis de la entonación del español lo terminaremos con la presentación del Análisis Melódico del Habla (Cantero, 2002; Cantero y Font-Rotchés, 2009, 2020). 
Este método nos parece especialmente eficaz a la hora de describir distintas circunstancias entonativas, por lo que permite, entre otros, analizar diversas lenguas e interlenguas. Dado que es un modelo todavía poco divulgado, a continuación, exponemos con más detalle sus principales rasgos.

Los precursores de este modelo indican que la entonación es un fenómeno complejo y podemos analizarlo desde la perspectiva prelingüística, lingüística y paralingüística. La entonación prelingüística, como un fenómeno discursivo, constituye el elemento integrador del habla. La lingüística permite estudiar las unidades fonológicas de carácter suprasegmental. Estas unidades, llamadas tonemas, están caracterizadas por los rasgos fonológicos binarios ( \pm interrogativa,

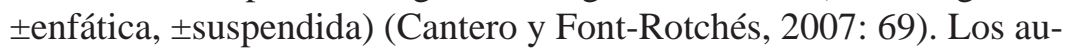
tores distinguieron 8 tonemas en español. La entonación paralingüística hace referencia a los márgenes de dispersión de los tonemas (que aportan más información sobre las realizaciones expresivas, emotivas e idiosincrásicas del hablante).

Basándose en un análisis muy profundo y completo, los autores del método clasificaron los patrones melódicos del español en cuatro categorías: entonación neutra, interrogativa, enfática y suspendida.

La entonación neutra, la que no está marcada por ningún rasgo fonológico positivo (-interrog. -enf. -susp.), no es muy frecuente en el habla espontánea. En la figura siguiente podemos ver el patrón melódico I que representa dicha entonación. 
Figura 1. Patrón melódico I (fuente: Cantero y Font-Rotchés, 2007: 73)

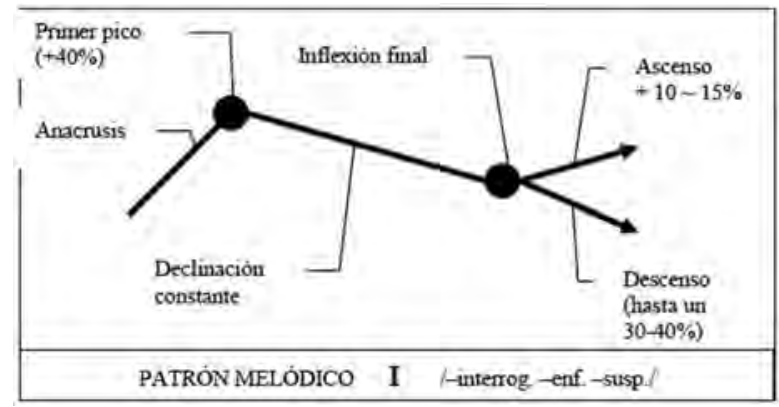

Este patrón melódico lo caracteriza el anacrusis (opcional) con un ascenso hasta el primer pico de hasta un $40 \%$. La primera vocal tónica del contorno, que representa el primer pico, se encuentra en el punto más alto de todo el contorno. El cuerpo presenta una declinación suave y constante y la inflexión final puede estar representada por un ascenso de entre $10-15 \%$ o un descenso de entre $30-40 \%$.

A la entonación interrogativa (+interrog. -enf. -susp.) corresponden cinco patrones melódicos con distintos gráficos. Los cuatro primeros se han expuesto en Cantero y Font-Rotchés (2007) y el último se ha añadido unos años después, en Font-Rotchés y Mateo (2013).

Figura 2. Patrón melódico II (fuente: Cantero y Font-Rotchés, 2007: 74)

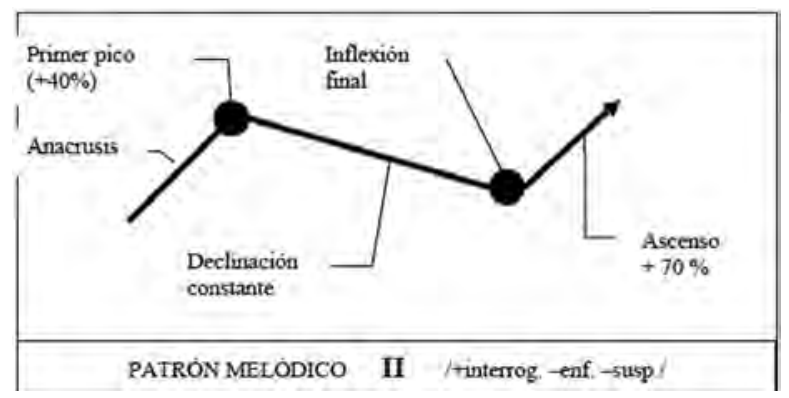


En el patrón melódico II, lo más característico es la inflexión final con un ascenso superior a un 70\%. Las demás características son similares a la entonación neutra.

El siguiente patrón melódico, también de la entonación interrogativa, se caracteriza por un ascenso final menos articulado (de entre 40$60 \%$ y un primer pico desplazado. Está representado en la siguiente figura.

Figura 3. Patrón melódico III (fuente: Cantero y Font-Rotchés, 2007: 74)

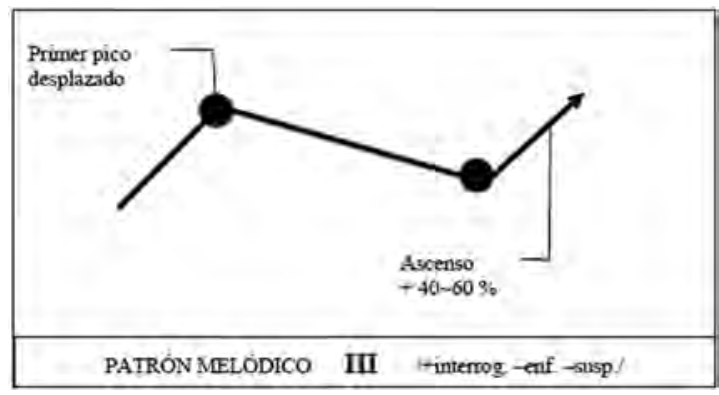

Los siguientes patrones melódicos, IVa y IVb, también interrogativos, están caracterizados por su inflexión final circunfleja ascendente-descendente. 
Figura 4. Patrones melódicos IVa y IVb (fuente: Cantero y Font-Rotchés, 2007: 75-76)
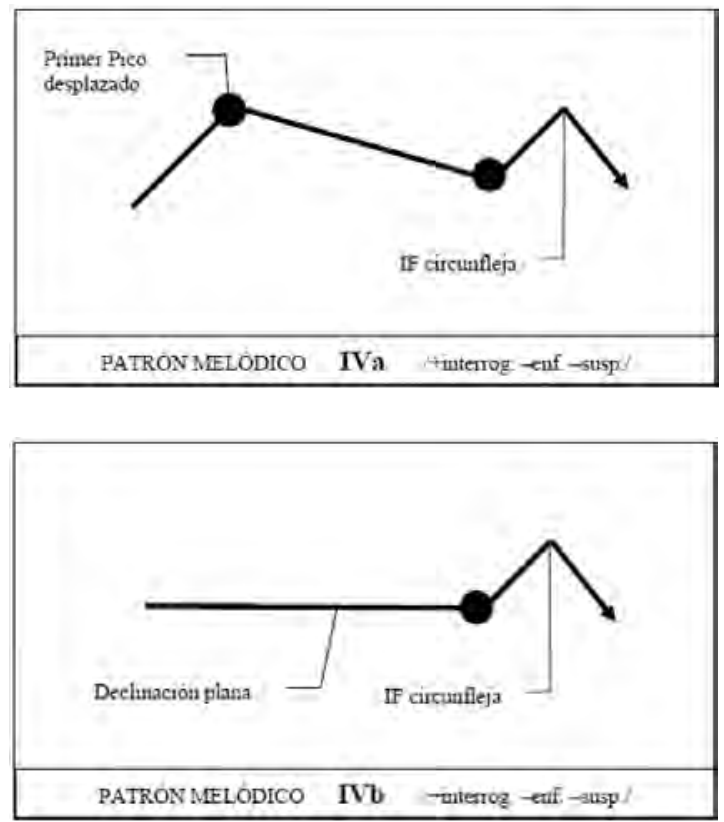

El patrón melódico IVa tiene el primer pico desplazado a la siguiente vocal tónica, el cuerpo descendente y una inflexión final circunfleja ascendente-descendente.

El patrón IVb está marcado por la falta del primer pico y un cuerpo plano, sin declinación. Su inflexión final también es circunfleja ascendente-descendente.

El último patrón melódico interrogativo, el patrón XIII está caracterizado por un cuerpo ascendente (a menudo sin primer pico) y una inflexión final ascendente. 
Figura 5. Patrón melódico XIII (fuente: Font-Rotchés y Mateo, 2013: 269)

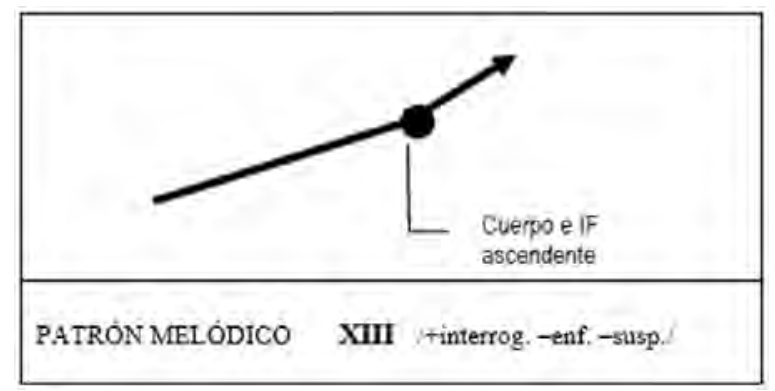

La entonación suspendida está caracterizada fonológicamente como (-interrog. -enf. +susp.) y la representan tres patrones melódicos.

Figura 6. Patrón melódico V (fuente: Cantero y Font-Rotchés, 2007: 77)

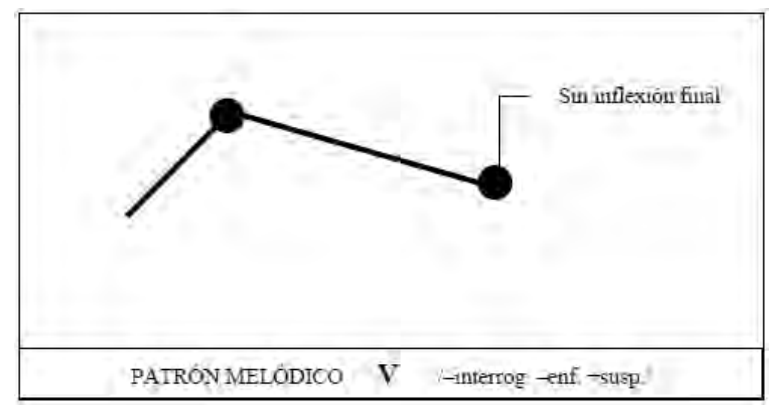

En esta melodía lo más notable es la falta de la inflexión final, lo que puede sugerirnos que las frases con esta entonación no suelen terminar los contornos.

Los siguientes patrones, VIa y VIb, tienen una inflexión final ascendente que parece no estar terminada. 
Figura 7. Patrones melódicos VIa y VIb (fuente: Cantero y Font-Rotchés, 2007: 77-78)

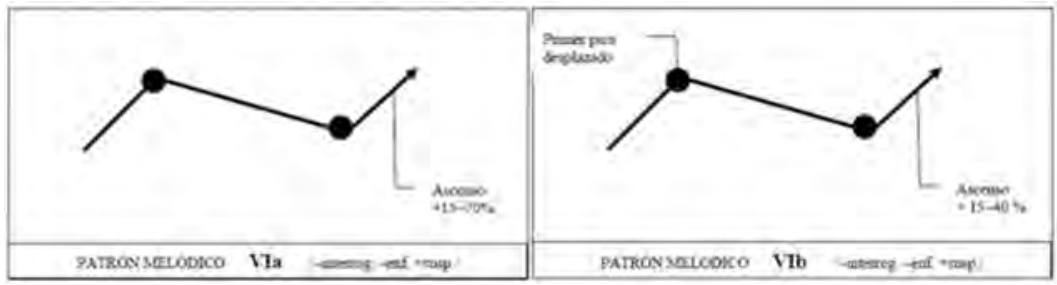

Estos dos patrones, aunque sus gráficos se parecen mucho, tienen sus características propias. El patrón melódico VIa está marcado por una inflexión final de entre $15-70 \%$, y el VIb la tiene más suave, entre 15-40\%. Cabe subrayar que en el patrón melódico VIb el primer pico está desplazado a la siguiente vocal átona.

La entonación enfática (-interrog., +enf., -susp.) permite al hablante expresar sus estados emocionales. Aquí los autores distinguieron 9 patrones melódicos. Los observaremos en las siguientes figuras.

Figura 8. Patrones melódicos VII y VIII (fuente: Cantero y Font-Rotchés, 2007: 79-80)

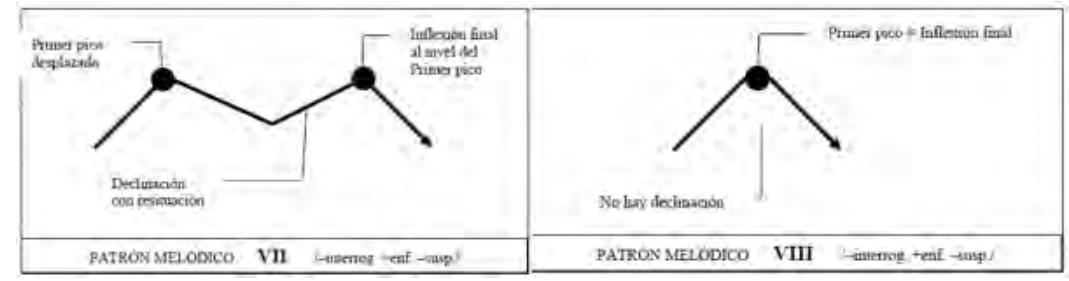

El patrón melódico VII tiene el anacrusis ascendente hasta le primer pico que está desplazado a la siguiente vocal átona. La declinación es descendente-ascendente para que la inflexión final llegue al nivel del primer pico. En el patrón VIII no hay declinación ya que el primer pico y la inflexión final se identifican, forman un segmento tonal. 
Los patrones melódicos IX, Xa, Xb y el XI están definidos en función de su inflexión final.

Figura 9. Patrón melódico IX (fuente: Cantero y Font-Rotchés, 2007: 80)

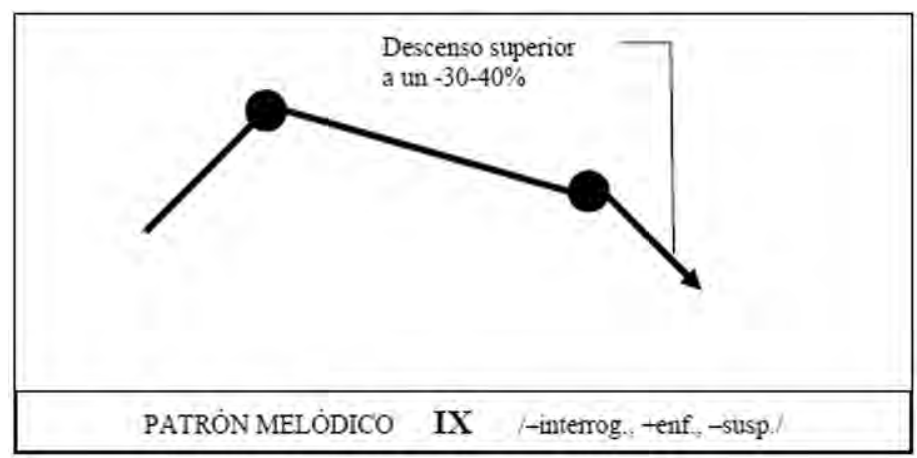

Lo más notable en el patrón melódico IX es la inflexión final con un descenso superior al 30\%. 
Figura 10. Patrones melódicos Xa i Xb (fuente: Cantero y Font-Rotchés, 2007:

81)
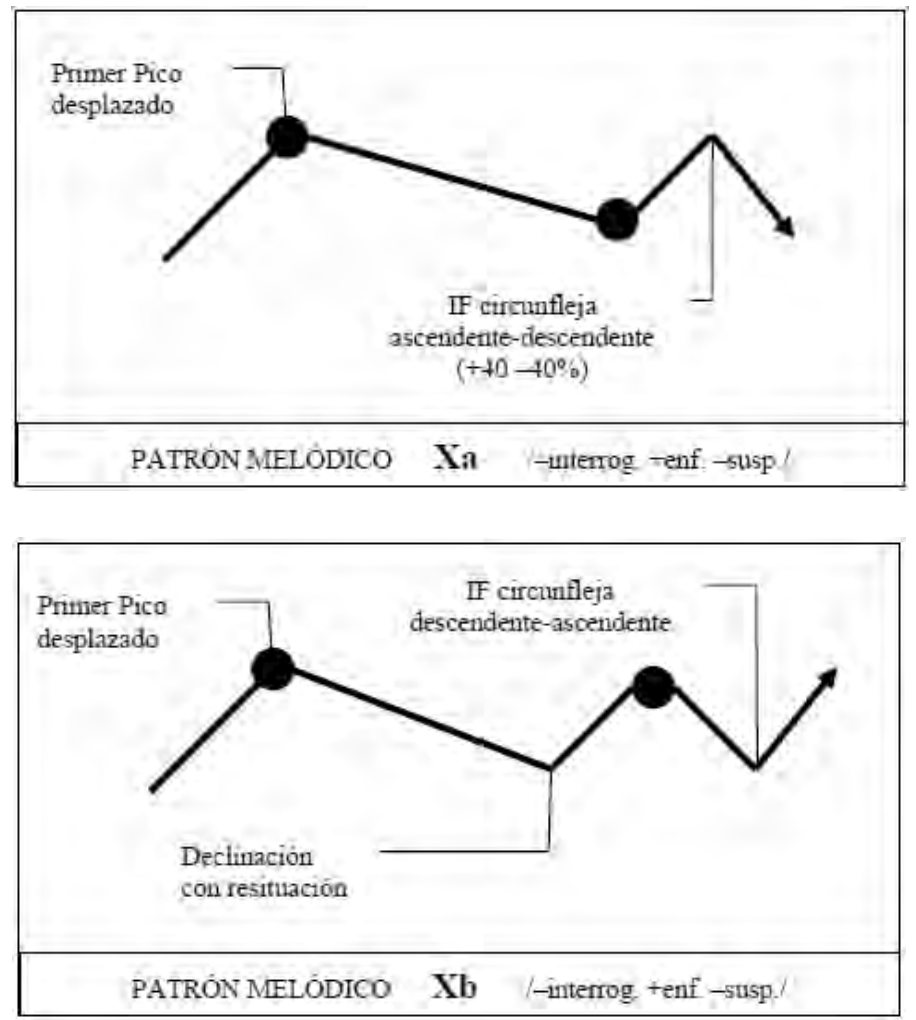

Como podemos observar en los patrones Xa i Xb, lo más visible es su inflexión final circunfleja, ascendente-descendente en Xa y descendente-ascendente en $\mathrm{Xb}$. En ambos patrones, el primer pico desplazado es un rasgo conjunto a la inflexión final circunfleja.

El siguiente patrón enfático, el patrón melódico XI, tiene un primer pico desplazado (con un gran ascenso) y la inflexión final ascendente (superior a un 60\%). Lo que es característico de esta melodía es una 
declinación quebrada en la que aparece un pico interior extra. Lo podemos observar en la siguiente figura.

Figura 11. Patrón melódico XI (fuente: Cantero y Font-Rotchés, 2007: 82)

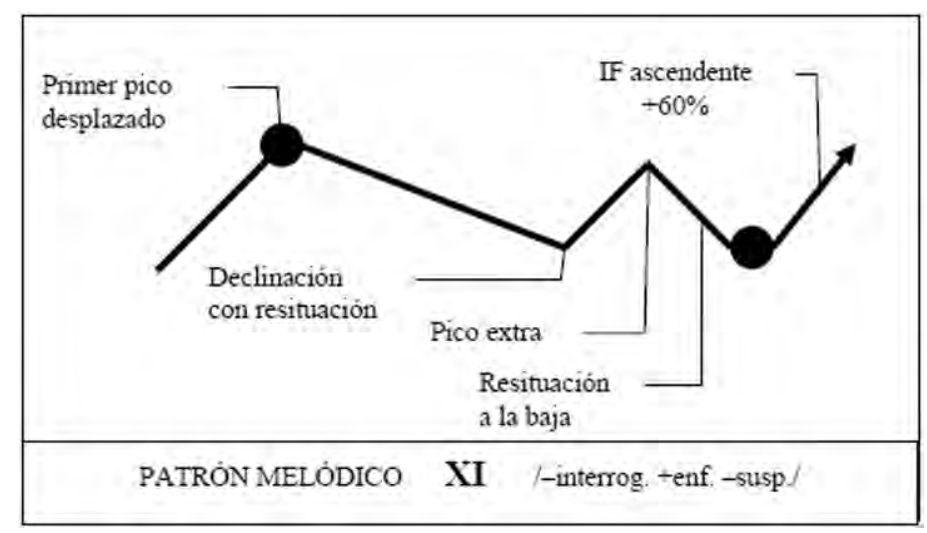

Los patrones melódicos XIIa, XIIb y XIIc están definidos por su declinación. 
Figura 12. Patrones melódicos XIIa, XIIb y XIIc (fuente: Cantero y Font-Rotchés, 2007: 83-84)
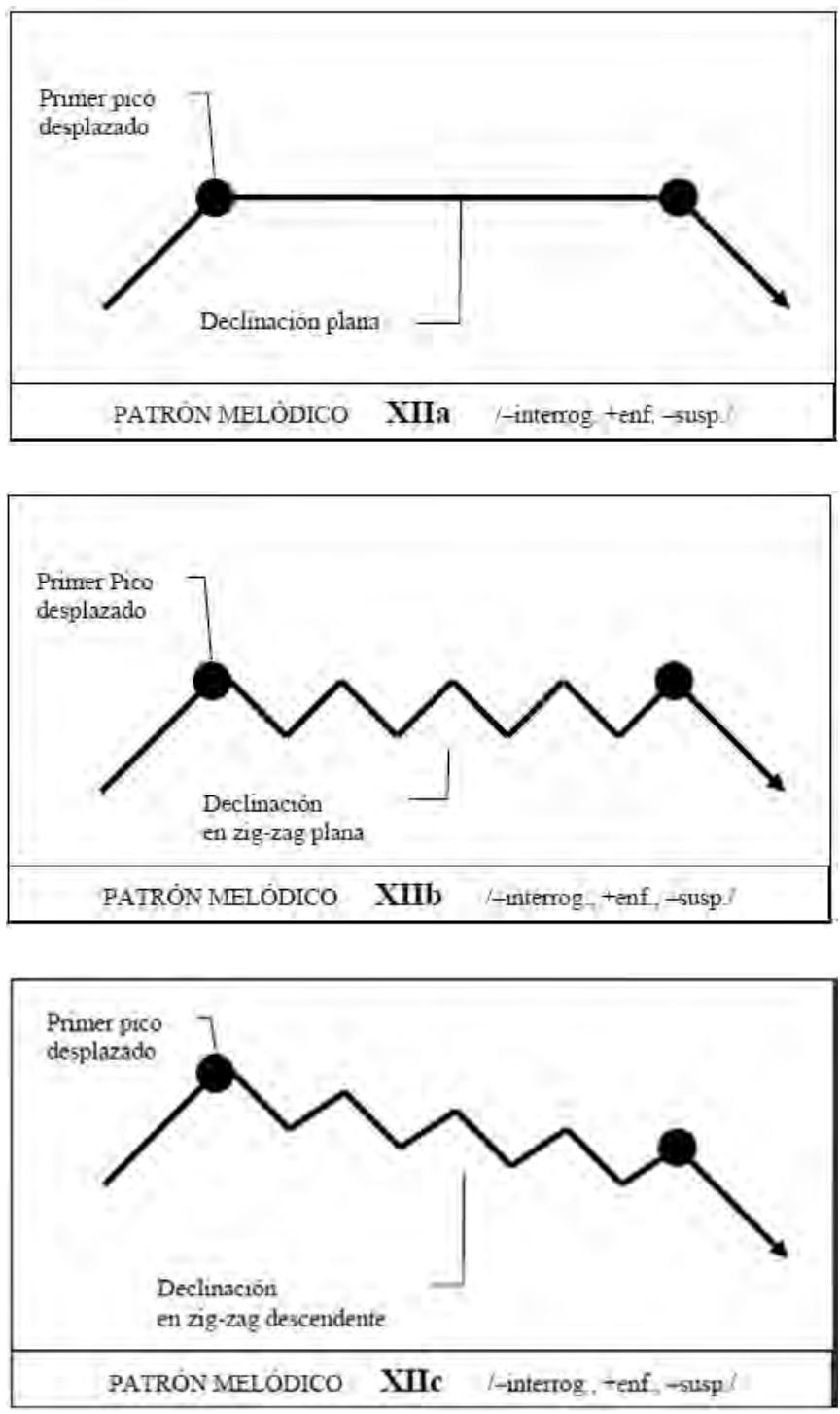
Como podemos observar, estos patrones melódicos tienen los primeros picos desplazados y las inflexiones finales descendentes. Se diferencian en el cuerpo del contorno, ya que el patrón XIIa lo tiene plano, con una declinación suave, mientras que los patrones XIIb y XIIc tienen los cuerpos con unas declinaciones en zig-zag (el patrón XIIb la tiene en forma plana, mientras que el XIIc descendente).

\section{El Análisis Melódico del Habla}

Como ya se ha expuesto, el Análisis Melódico del Habla es un método que permite al investigador llevar a cabo una descripción completa y precisa de la entonación de una lengua o interlengua. Ofrece una interpretación fonológica, no dependiente de otros niveles de análisis lingüísticos, lo que es muy importante y útil cuando se trabaja con el habla espontánea. Otra característica fundamental que lo diferencia de otros métodos es que ofrece un sistema de procesamiento de los datos acústicos que da la posibilidad de obtener los valores relativos de las melodías para poder compararlos, clasificarlos y reproducirlos (Cantero y Font-Rotchés, 2009: 34). Entre las características que diferencian este método de los demás, Cantero y Mateo (2011) enumeran también el hecho de la posibilidad de añadir cualquier tipo de notación en los enunciados (después del análisis melódico). Esa oportunidad permite analizarlos y transcribirlos de manera pragmática, gramatical o léxica ya que es un modelo abierto. Los autores subrayan, asimismo, la enorme utilidad de este método, dado que posibilita trabajar no solo con la entonación de las lenguas o interlenguas, sino también con la prosodia limitada a un ámbito concreto, por ejemplo, los eslóganes publicitarios o las locuciones profesionales, entre otros. Gracias a esos criterios podemos trabajar con gran número de informantes y elaborar un corpus muy amplio y fiable. Contar con múltiples contornos nos permite establecer los patrones melódicos de una lengua o interlengua, nos da la posibilidad de comparar las líneas melódicas del corpus analizado con los patrones melódicos ya establecidos. Cabe subrayar otra vez que se trabaja con el habla espontánea de varios informantes, sin realizar una selección estricta de ellos, de ahí que tales variables 
como el sexo, la edad o la formación no revistan importancia (Cantero y Mateo, 2011: 7). El AMH examina los contornos de contextos lingüísticos naturales, por lo tanto, la espontaneidad de los hablantes es un factor de suma importancia. En cambio, los investigadores que trabajan con la entonación según otras metodologías, muchas veces la estudian en laboratorios influyendo en ocasiones en los informantes, es decir, pueden mostrarles qué y cómo deben pronunciar. Sus fines son puramente científicos, no obstante, las modificaciones y sugerencias de los investigadores pueden hacer que se pierda la claridad y transparencia de los resultados obtenidos.

El AMH nos permite trabajar con una lengua viva y real, lo que en el proceso de aprendizaje es un elemento crucial. Este método ha encontrado su aplicación en diversas áreas, para trabajar la pronunciación y la melodía de un idioma, para analizar la voz y tratar los trastornos de habla, entre otros. La metodología desarrollada y descrita por los investigadores barceloneses (Cantero, 2002; Font-Rotchés, 2007) ha tenido una buena acogida entre los lingüistas, profesores e investigadores interesados en trabajar la entonación.

Según el protocolo de AMH (Cantero y Font-Rotchés, 2009, 2020), la aplicación del método se divide en dos fases: la fase acústica y la fase perceptiva.

\section{a) Fase acústica}

La fase acústica consiste en analizar detalladamente las frecuencias fundamentales $\left(\mathrm{F}_{0}\right)$ de cada vocal. Gracias a una herramienta fiable que permite hacer un análisis acústico, el software Praat (Boersma y Weenink, 1992-2018), es posible diferenciar los valores relevantes (de las vocales) de los irrelevantes (p. ej. de las consonantes). La siguiente figura representa un gráfico del sonograma y la frecuencia fundamental $\left(\mathrm{F}_{0}\right)$ del enunciado interrogativo ¿Has hablado con tu madre? emitido por un estudiante polaco. Las áreas oscuras del espectrograma corresponden a los segmentos vocálicos (o diptongos). Esta visualización nos sirve de guía para extraer los valores importantes para el análisis posterior. 
Figura 13. El sonograma del enunciado ¿Has hablado con tu madre? (corpus de elaboración propia del español hablado por polacos)

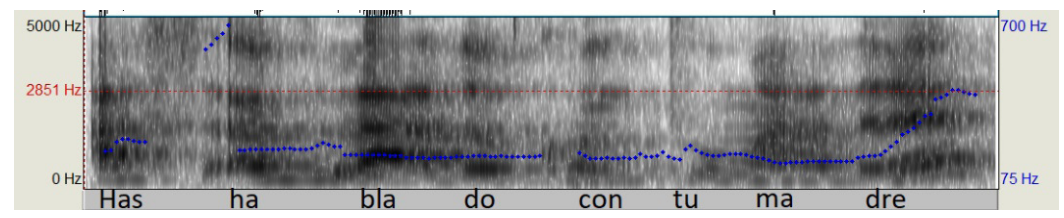

Hay que mencionar que hay situaciones donde una vocal tiene dos o incluso tres valores. Podemos hablar de más de un segmento tonal cuando la distancia tonal entre un valor y el otro, de la misma vocal, es superior al 10\% (el 100\% es equivalente a una octava de la escala musical). Esta situación de una inflexión circunfleja puede ser encontrada en cualquier parte del contorno. Según las pruebas de los investigadores, Cantero y Font-Rotchés, para describir la entonación lingüística, solo debemos utilizar los datos de inflexión tonal muy marcados (un $20 \%$ de cambio tonal). Sin embargo, Cantero y Font-Rotchés (2020: 27 ) mencionan que, para el análisis de los dialectos o de las interlenguas, una distancia tonal de un 10\% (como mínimo) ya es significativa y evidente. Estas pequeñas características ya nos permitirían describir los rasgos de una interlengua u observar la influencia de la lengua materna en la lengua meta.

En cuanto al enunciado que hemos escogido para la presentación del análisis en la fase acústica podemos observar que la inflexión final del contorno representa un ascenso relevante que tiene lugar en la última sílaba "dre" (de la palabra "madre"). Como vemos, en este caso, ambos valores de esta vocal resultan importantes.

Los valores absolutos extraídos a partir del espectrograma mediante el software PRAAT todavía no forman las melodías de los contornos ya que siguen siendo marcadas por las características fonéticas individuales de cada informante (p. ej., el tono de la voz femenina y masculina es distinto). Los datos tienen que estar relativizados y por eso las cifras que indican el tono en Herzios se pasan a los porcentajes asignando siempre el número 100 al primer valor del enunciado. Los 
porcentajes nos informan sobre los valores relativos de los elementos de cada contorno (se calculan sin tener en cuenta las variables sociolingüísticas del informante).

Figura 14. Los valores tonales (en Hertz) de los segmentos del contorno interrogativo ¿Has hablado con tu madre? (corpus de elaboración propia del español hablado por polacos)

\begin{tabular}{|c|c|c|c|}
\hline Segmentos & $\begin{array}{c}\text { Hertz } \\
\text { (valores absolutos) }\end{array}$ & $\begin{array}{c}\text { Porcentaje } \\
\text { (valores relativos) }\end{array}$ & $\begin{array}{c}\text { Valores estandari- } \\
\text { zados }\end{array}$ \\
\hline Has & 246 & $100,0 \%$ & 100 \\
\hline Ha & 215 & $-12,6 \%$ & 87 \\
\hline Bla & 195 & $-9,3 \%$ & 79 \\
\hline Do & 190 & $-2,6 \%$ & 77 \\
\hline Con & 184 & $-3,2 \%$ & 75 \\
\hline Tu & 196 & $6,5 \%$ & 80 \\
\hline Ma & 171 & $-12,8 \%$ & 70 \\
\hline Dre & 266 & $55,6 \%$ & 108 \\
\hline dre* & 385 & $44,7 \%$ & 157 \\
\hline
\end{tabular}

Para dibujar la representación gráfica de cada melodía, hay que convertir los porcentajes obtenidos en valores estándar comenzando con el valor 100 (un valor arbitrario). Así podemos observar que el siguiente valor que muestra un descenso de un 12,6\% tendrá el valor estándar de 87, después vemos un descenso de un 9,3\%, lo que nos dará un valor estándar de 79, y así lo contamos hasta el último valor.

Calculando todos los valores según las fórmulas expuestas en Cantero y Font-Rotchés 2020, obtenemos el gráfico en Excel que demuestra las distancias tonales entre los segmentos y visualiza la línea melódica del enunciado. En la figura 15 podemos ver la línea melódica del enunciado anterior. 
Figura 15. La línea melódica del enunciado interrogativo ¿Has hablado con tu madre? (corpus de elaboración propia del español hablado por polacos)

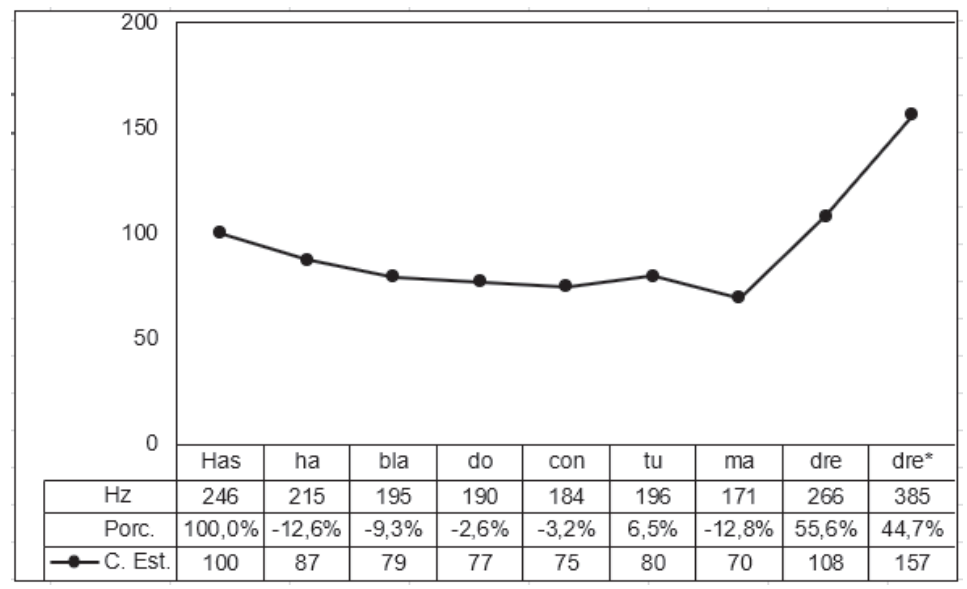

En la fase acústica debemos, en primer lugar, establecer de forma clara los segmentos tonales (Cantero y Mateo, 2011). Gracias al análisis realizado de esta manera, es posible obtener un contorno estandarizado que permite hacer una comparación y clasificación, independientemente de la edad, el sexo u otra característica del informante. Cabe mencionar también que dicho estudio, desde una perspectiva melódica, permite comparar los contornos de diferente longitud, ya que lo que resulta importante es el número de los valores tonales y no sus inflexiones y la melodía que describen (Cantero, 2020).

\section{b) Fase perceptiva}

La fase perceptiva se refiere al análisis de las curvas melódicas comparándolas con los patrones melódicos existentes en español. En esta fase se determinan tanto los rasgos melódicos como los márgenes de dispersión característicos de la lengua o interlengua estudiada. Para la correcta interpretación del contorno melódico analizado desde esta perspectiva, es necesario tener en cuenta los patrones del español 
peninsular. Sus márgenes de dispersión descritos por Cantero y FontRotchés (2007) permiten comparar cualquier enunciado emitido en la interlengua investigada y observar si la línea melódica coincide con algún patrón melódico de la lengua meta.

Gracias a estas dos fases es posible aislar los "segmentos tonales" relevantes en la constitución de la melodía, lo cual, a su vez, permite realizar una comparación entre diversos hablantes y diversas lenguas o interlenguas (Cantero, 2019).

El Análisis Melódico del Habla distingue tres tipos de funciones o niveles de análisis de la entonación: lingüística, prelingüística y paralingüística. Quilis en 1981 hablaba de la "función integradora, delimitadora" de la entonación y a partir de esta definición podemos entender la entonación prelingüística como un elemento clave tanto en la integración como en la fragmentación y comprensión del discurso. La entonación paralingüística, tal como indica su nombre, sirve para expresar la actitud y el estado de ánimo del interlocutor. La entonación lingüística, o sea, la interpretación fonológica de la melodía está definida mediante la oposición de tres rasgos: interrogativo, enfático y suspendido. Cada uno de estos niveles puede estudiarse por separado, pero al mismo tiempo funcionan muy bien coestructurados. El AMH permite trabajar detalladamente con cada uno de estos niveles, no obstante, muestra también sus correlaciones y permite comprender y examinar sus relaciones entre sí tratando la entonación como un complejo (una unidad compuesta de estos tres niveles).

A lo largo de cada análisis melódico, las funciones clave de la entonación serán la prelingüística y la lingüística. La entonación prelingüística nos permite estructurar el discurso e integrarlo en unidades concretas, observando las características melódicas de los contornos. Lo que caracteriza la melodía de una frase española es un primer pico alto formado normalmente por una vocal tónica, el cuerpo descendente (a veces con algunas inflexiones circunflejas introducidas siempre por algunas tónicas) y la inflexión final descendente (por lo menos -15\%) o ascendente (hasta unos $+120 \%$ ) (Cantero y Font-Rotchés, 2020: 37). La entonación lingüística permite definir los contornos concretos que se diferencian de otros, también concretos. Esa definición se realiza 
observando los rasgos distintivos de cada una de ellas (Cantero y Mateo, 2011). Hablamos aquí de las melodías de los nativos aplicadas en ciertos contextos comunicativos que puedan convertirse en modelos de producción y percepción para los que aprenden una lengua.

En la entonación lingüística, los autores del método enumeran dos tipos de rasgos en la entonación: los rasgos melódicos (fonéticos) y los rasgos fonológicos que ofrecen la división de las unidades fonológicas en tonemas. En el AMH se definen tres rasgos fonológicos binarios ( \pm interrogativo, \pm enfático, \pm suspendido) y al combinar estos tres rasgos, Cantero (2002: 142-143) ha distinguido 8 tonemas en español:
1. /+interrog., +enfát., +susp./
2. /+interrog.,+enfát., -susp./
3. /+interrog., -enfát., +susp./
4. /+interrog., -enfát., -susp./
5. /-interrog., +enfát., +susp./
6. /-interrog., +enfát., -susp./
7. /-interrog., -enfát., +susp./
8. /-interrog., -enfát., -susp./

Según esta clasificación, la entonación neutra se identificará con el tonema 8, la interrogativa con el 4, la suspendida con el 7 y la enfática con el 6. Cada uno de estos ocho tonemas puede estar expresado por distintas melodías (que tienen definidos unos márgenes de dispersión muy concretos). Las melodías que son las más frecuentes en una lengua se llaman los patrones melódicos (los del español están descritos en Cantero y Font-Rotchés, 2007; Font-Rotchés y Mateo, 2013, 2017). Los autores mencionan hasta trece patrones melódicos típicos para el español peninsular clasificados según los rasgos interrogativo, enfático y suspendido. Para poder analizar bien la melodía de la entonación con la que trabajamos tenemos que fijarnos también en los márgenes de dispersión propios de cada uno de los patrones. Los fundadores del AMH indican que el patrón melódico del enunciado neutro (es decir, no marcado como interrogativo, enfático o suspendido) puede tener la inflexión final descendente (hasta un 30\% de descenso) o ascendente (hasta un 15\% de ascenso). Si los valores tonales sobrepasan estos números, la melodía cambia y la clasificamos como suspendida (ascenso 
final de entre 15 y $70 \%$ ), interrogativa (con el ascenso superior a un $70 \%$ ) o enfática (con el descenso final mayor a un 30\%) (Cantero y Font-Rotchés, 2007: 72). Estos márgenes de dispersión del patrón permiten al oyente comprender los enunciados e interpretar bien las intenciones y emociones del hablante.

Cantero y Font-Rotchés (2009: 29) subrayan en el Protocolo para el análisis melódico del habla que:

Según nuestro método, el patrón melódico no es una mera representación de una línea con ascensos y descensos, sino que es una abstracción de la realidad hablada, representativa de múltiples melodías con los rasgos melódicos comprendidos entre sus márgenes de dispersión.

Cada enunciado se analiza teniendo en cuenta las tres partes de cada contorno: anacrusis, cuerpo e inflexión final, y dos acentos, el primer pico y el núcleo (presentados en la figura 16). La anacrusis está formada por los primeros segmentos tonales ascendentes que culminan en la primera vocal tónica o primer pico. El cuerpo es la parte de contorno que va desde el primer pico hasta la última vocal tónica, llamada núcleo; y la inflexión final empieza en el núcleo y continúa hasta el final del contorno.

Cada una de las partes del contorno tiene su relevancia en el análisis, el cual debe ser completo, es decir, no se puede comentar y clasificar el contorno según solo una parte del mismo, sino que es necesario fijarse en toda la curva melódica compuesta por estas tres partes inseparables.

Gracias a que la metodología del Análisis Melódico del Habla permite analizar cualquier idioma es posible aplicarla en el ámbito didáctico para trabajar con la pronunciación y entonación mejorando las competencias orales de los estudiantes. Siguiendo este método, el profesor dispone de una herramienta adecuada, completa y segura para comparar los enunciados emitidos por sus discípulos con los patrones melódicos propios de la lengua meta, en el caso de este trabajo, del español (hablado por polacos). Esta posibilidad ofrece disminuir los malentendidos provocados por hablar con una melodía inadecuada. Surge, a menudo, que un estudiante, a pesar de que su dominio de la 
lengua es relativamente alto, no es capaz de producir una interrogación o una enfática en español de tal modo que su melodía se acerque a los patrones melódicos típicos del español. Sin contexto comunicativo, sus enunciados podrían interpretarse como suspendidos o neutros.

Figura 16. Esquema de las tres partes del contorno en Cantero y Font-Rotchés (2007: 70)

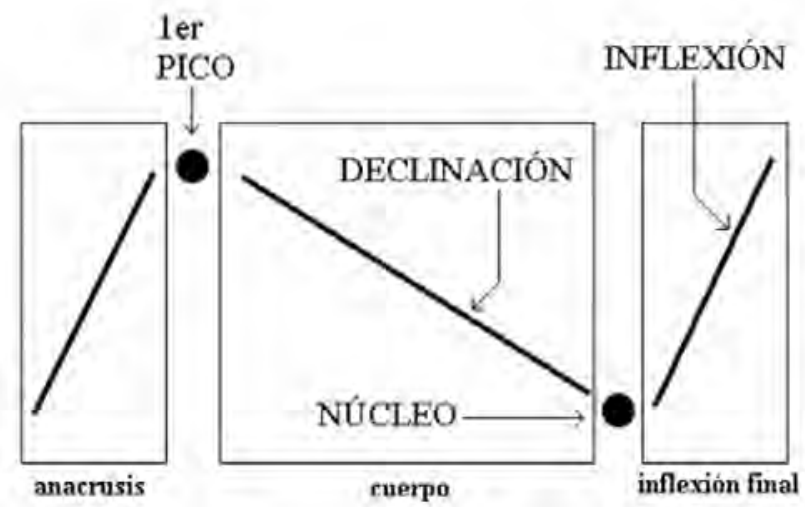

\section{La presentación del método a partir de la descripción de ejemplos concretos}

Tras una detallada descripción teórica del método sería conveniente poder ver cuál es su aplicación práctica, es decir, averiguar qué información podemos extraer a partir de los enunciados examinados. A lo largo del presente texto hemos observado paso a paso el análisis de un enunciado interrogativo ¿Has hablado con tu madre? (figura 15). Dicho ejemplo forma parte de un corpus mucho más amplio que constituirá la base para el análisis de la interlengua, el español hablado por polacos, y será presentado en la tesis doctoral en la Universidad de Barcelona. La investigación completa mostrará los resultados de la entonación de los enunciados pronunicados por polacos en comparación con los patrones melódicos españoles, con desglose en los enunciados 
neutros, interrogativos, suspendidos y enfáticos. Dado que hasta el momento actual hemos trabajado más con las frases interrogativas, a continuación presentamos tres ejemplos de las mismas a fin de observar sus principales características.

Entre los patrones melódicos interrogativos del español peninsular descritos según la metodología AMH (Cantero y Font-Rotchés, 2007; Font-Rotchés y Mateo, 2013, 2017) se han distinguido cuatro y son los siguientes: Patrón II Inflexión Final ascendente $+70 \%$; Patrón III Inflexión Final ascendente 40\%-70\%; Patrón IV Inflexión Final ascendente-descendente; y Patrón XIII Cuerpo e Inflexión Final ascendentes. Analizando los ejemplos de las interrogativas absolutas de nuestro corpus, hay que tener en cuenta los rasgos significativos en cada parte del contorno: anacrusis, primer pico, cuerpo, núcleo e inflexión final.

Empecemos a observar con más detalle el enunciado ¿Has hablado con tu madre? en la figura $15 \mathrm{del}$ apartado anterior.

Este enunciado lo clasificamos como interrogativo dado que esta ha sido su función en el contexto comunicativo. El examen nos permite verificar si el informante lo ha producido con una entonación adecuada para las interrogativas del español o no. Lo que llama nuestra atención en esta línea melódica es, sin duda, su inflexión final muy marcada, que supera el $100 \%$. En este contorno falta el primer pico y su cuerpo presenta un descenso suave. Esta línea melódica se acerca al patrón melódico II (véase, figura 2). Aunque en este patrón melódico (como también en los otros) observamos un primer pico a partir del cual el cuerpo desciende constantemente, lo más importante es la subida muy notable en la inflexión final. En el caso de esta melodía basta con analizar el ascenso de la inflexión final para poder clasificar un contorno como una interrogativa. Así pues, el ejemplo aquí presentado lo interpretamos directamente como pregunta, ya que su inflexión final está muy marcada. Por lo tanto, podemos concluir que el emisor ha logrado su objetivo comunicativo no solo teniendo en cuenta el contexto situacional, sino también asignando una entonación adecuada a lo que estaba expresando.

Entre los patrones melódicos interrogativos encontramos el Patrón III con una inflexión final ascendente entre un 40\%-70\%. El 
patrón II, anteriormente descrito, nos permitía clasificar un enunciado acorde con él solo fijándonos en la inflexión final (que debe superar el $70 \%$ ). En el patrón III debemos concentrarnos no solo en la inflexión final (de entre un $40 \%$ y un $70 \%$ ) sino también en el primer pico, que suele estar desplazado a una sílaba átona posterior a la primera tónica. En nuestro corpus analizado hasta el momento hemos obtenido enunciados con la inflexión final acorde con el patrón III, pero pocos de ellos presentan el primer pico. Cabe mencionar, tras las primeras observaciones del corpus analizado, que la falta del primer pico parece ser un rasgo característico de la interlengua español hablado por polacos (y también de otras, como el español hablado por italianos (Devís, 2011) o brasileños (Fonseca, 2013)). En la figura 17 observamos un enunciado con una inflexión final de un $66 \%$, con un cuerpo muy plano y sin primer pico.

Figura 17. La línea melódica del enunciado interrogativo ¿Tus mujeres necesitan el dinero?

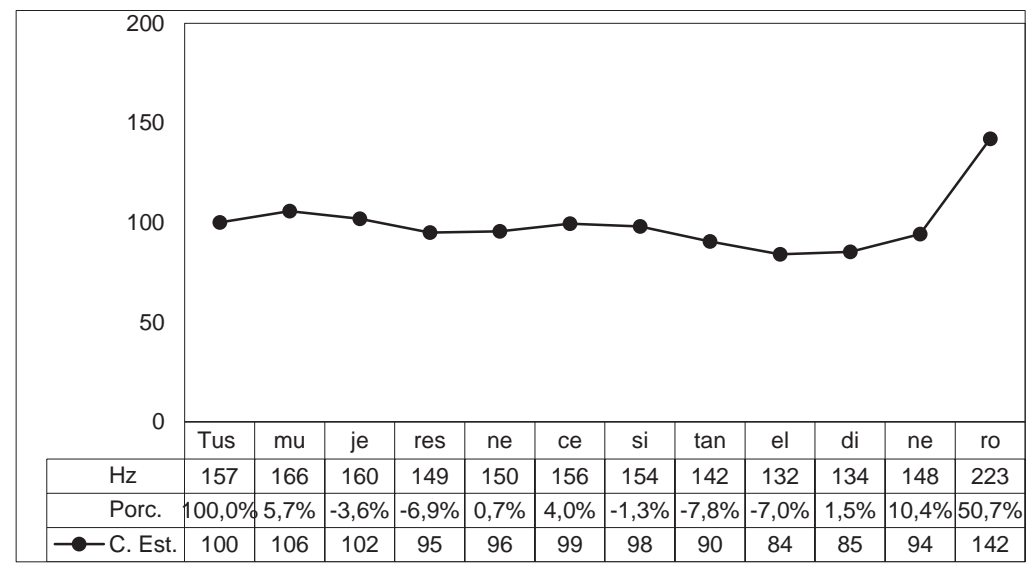

Dado que los contornos de este grupo, en la mayoría de los casos, carecen del primer pico, es muy probable que sean interpretados como 
enunciados no acabados, en lugar de interrogativos (van acercándose al patrón suspenso VIb del español, Cantero y Font-Rotchés (2007)).

El ejemplo de la figura 17 estaba producido con una intención comunicativa de proponer una pregunta al interlocutor, pero, como hemos visto, sus características entonativas podrían confundir a un nativo y ser entendido como una suspendida. En el corpus actual tenemos también varios enunciados cuyo fin comunicativo era interrogativo pero su entonación no se asemeja a ningún patrón melódico español interrogativo sino más bien al patrón VI (véase, la figura 7) cuyos rasgos se corresponden con los contornos suspendidos. En la figura 18 podemos ver un contorno producido como una interrogativa pero con una melodía más acorde con el patrón suspendido que con cualquier interrogativo. Su cuerpo es muy plano y la inflexión final muy leve. En este caso el emisor no consigue su intención comunicativa.

Figura 18. La línea melódica del enunciado interrogativo ¿Y lo de llevar una vida activa? (corpus de elaboración propia del español hablado por polacos)

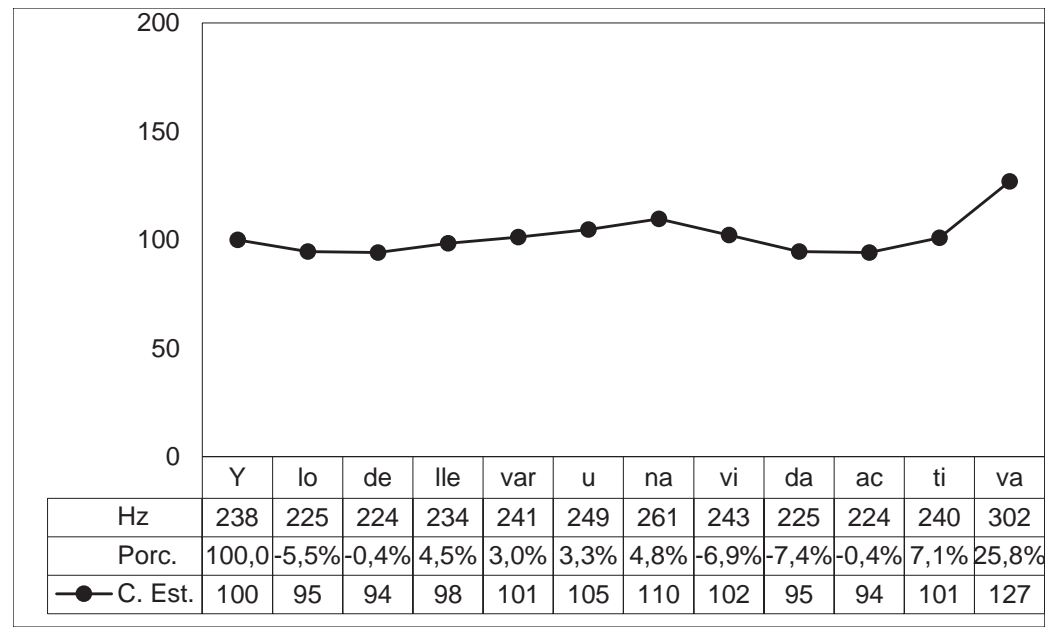

Para terminar, cabe destacar que a lo largo de la investigación realizada hasta el momento, han aparecido también contornos similares 
a los patrones enfáticos, sin embargo, la intención del hablante ha sido distinta, más bien interrogativa.

\section{Conclusiones}

A lo largo de nuestro artículo hemos venido presentando de manera muy detallada un modo relativamente nuevo de análisis de la entonación que puede aplicarse a cualquier idioma o interlengua. Nuestras propias observaciones, llevadas a cabo en las universidades de Polonia, nos autorizan a constatar que el Análisis Melódico del Habla es un método poco conocido en el ámbito universitario polaco, por lo que nos encantaría que el presente texto despertara más interés sobre la entonación, un fenómeno lingüístico que todavía parece estar relegado a un segundo plano. Esta metodología nos da una gran oportunidad para trabajar con las melodías de los enunciados españoles espontáneos emitidos por los polacos, nos ayuda a analizarlas detalladamente y a compararlas con los patrones melódicos españoles. Los datos exactos sobre la entonación, obtenidos a partir del análisis acústico descrito, nos permitirá relevar cuáles son los rasgos que favorecen que un enunciado emitido por un hablante de español polaco en un contexto comunicativo determinado pueda ser entendido por los nativos y cuáles son los rasgos que pueden provocar malentendidos. Esperamos que la investigación del corpus completo aporte mucha información sobre la entonación del español hablado por polacos y tras su aplicación a la didáctica de ELE en Polonia ayude a los estudiantes a mejorar su entonación y ser comunicativamente más eficaces.

\section{Bibliografía}

AERA (2011), Code of Ethics, [on-line] https://cdn.ymaws.com/www.weraonline.org/resource/resmgr/a_general/aera.pdf, 2.06.2020.

BADITZNÉ PÁLVÖGYI, K. (2012), Spanish Intonation of Hungarian Learners of Spanish: Yes or No Questions, Tesis doctoral, Biblioteca Phonica, 
15, [on-line] http://www.publicacions.ub.edu/revistes/phonica-biblioteca/ 15_kata.pdf, 2.05.2020.

BOERSMA, P., WEENINK, D. (1992-2018), Praat: Doing Phonetics by Computer (Computer program), Version 6.1.02., [on-line] http://www. praat.org, 2.05.2020.

BOWEN, J. D. (1956), “A Comparison on the Intonation Patterns of English and Spanish”, Hispania, 39 (1), pp. 30-35.

CABRERA-ABREU, M. (1991), The Forms of Intonation: An Overview of Spanish, University College London/University of London, London.

CANTERO SERENA, F. J. (2002), Teoría y análisis de la entonación, Edicions Universitat de Barcelona, Barcelona.

CANTERO SERENA, F. J. (2003), “Fonética y didáctica de la pronunciación”, en: Mendoza, A. (coord.), Didáctica de la lengua y la literatura, Prentice Hall, Madrid, pp. 545-572.

CANTERO SERENA, F. J. (2019), “El Análisis Prosódico del Habla: más allá de la melodía”, en: Álvarez-Silva, M. R., Muñoz Alvarado, A., Ruiz Miyares, L., Comunicación Social: Lingüística, Medios Masivos, Arte, Etnología, Folclor y otras ciencias afines, vol. II, Ediciones Centro de Lingüística Aplicada, Santiago de Cuba, pp. 485-498.

CANTERO SERENA, F. J., FONT-ROTCHÉS, D. (2007), “Entonación del español peninsular en habla espontánea: Patrones melódicos y márgenes de dispersión”, Moenia, 13, pp. 69-92.

CANTERO SERENA, F. J., FONT-ROTCHÉS, D. (2009), "Protocolo para el análisis melódico del habla”, Estudios de fonética experimental, 18, pp. 17-32.

CANTERO SERENA, F. J., FONT-ROTCHÉS, D. (2020), "Melodic Analysis of Speech (MAS). Phonetics of Intonation”, en: Abasolo, J., de Pablo, I., Ensunza, A., Contributions on Education, Editorial de la Universidad del País Vasco, Bilbao, pp. 20-47.

CANTERO SERENA, F. J., MATEO, M. (2011), “Análisis Melódico del Habla: complejidad y entonación en el discurso”, Oralia, 14, pp. 105-127. DEVÍS HERRÁIZ, E. (2011), "La entonación del español hablado por italianos”, Didáctica. Lengua y Literatura, 23, pp. 35-58, https://doi. org/10.5209/rev_DIDA.2011.v23.36309. 
ELORDIETA, G. (1999), "Primer estudio comparativo de la entonación de tres variedades dialectales vascas”, Actas del I Congreso de Fonética Experimental, Universitat Rovira i Virgili/Universitat de Barcelona, Barcelona, pp. 209-215.

FONSECA DE OLIVEIRA, A. (2013), Caracterización de la entonación del español hablado por brasileños, Tesis doctoral, [on-line] http://diposit. ub.edu/dspace/handle/2445/54688, 2.05.2020.

FONT-ROTCHÉS, D. (2007), L'entonació del català. Publicacions de l'Abadia de Montserrat, Barcelona.

FONT-ROTCHÉS, D., MATEO, M. (2013), “Entonación de las interrogativas absolutas del español peninsular del sur en habla espontánea”, Onomázein, 28, pp. 256-275.

FONT-ROTCHÉS, D., MATEO, M. (2017), "Melodías para confirmar, preguntar, sugerir o pedir en español”, Phonica, 13, pp. 49-67.

GARCÍA LECUMBERRI, M. L. (2003), “Análisis por configuraciones: la escuela británica”, en: Prieto, P. (ed.), Teorías de la entonación, Ariel, Barcelona, pp. 35-63.

GARCÍA RIVERÓN, R. (1996), Aspectos de la entonación hispánica, Universidad de Extremadura, Cáceres.

GARRIDO ALMIÑANA, J. M. (1996), Modelización de patrones melódicos del español para la síntesis y el reconocimiento del habla, Universitat Autònoma de Barcelona, Barcelona.

GIL, J. (2007), Fonética para profesores de español: de la teoría a la práctica, Arco Libros, Madrid.

HIDALGO, A. (1997), La entonación coloquial. Función demarcativa y unidades del habla, Universidad de Valencia, Valencia.

KAO, W. L. (2011), La entonación de enunciados declarativos e interrogativos en chino mandarín hablado por taiwaneses, MA Research Project, Universitat de Barcelona, [on-line] http://diposit.ub.edu/dspace/bitstream/2445/17185/1/Proyecto\%20final\%20de\%20master\%20DLL\%20 2011\%20Weili\%20Kao\%20arreglado.pdf, 14.05.2020.

MARTÍNEZ CELDRÁN, E., FERNÁNDEZ PLANAS, A. M. (coords.) (2003-2018), Atlas Multimèdia de la Prosòdia de l'Espai Romànic, [on-line] http://stel.ub.edu/labfon/amper/cast/index_ampercat.html, 12.05.2020. 
MARTÍNEZ CELDRÁN, E., FERNÁNDEZ PLANAS, A. M. (2007), Manual de fonética española, Ariel, Barcelona.

MARTORELL, L., FONT-ROTCHÉS, D. (2015), Intonation Analysis of Spanish Spoken by Swedish Speakers: Declarative Utterances, Póster de una conferencia, https://doi.org/10.13140/RG.2.2.24686.46406.

MORA GALLARDO, E., ASUAJE, R. A. (2009), El canto de la palabra: una iniciación al estudio de la prosodia, Universidad de los Andes, Mérida.

NAVARRO, T. (1944), Manual de entonación española, Columbia University Press, New York.

PRIETO, P. (ed.) (2003), Teorías de la entonación, Ariel, Barcelona.

PRIETO, P. (2011), "Pitch Range, Gestural Information, and Perceived Politeness in Catalan", Journal of Pragmatics, 43, pp. 841-854.

QUILIS, A. (1981), Fonética acústica de la lengua española, Gredos, Madrid. SILVA-FUENZALIDA, I. (1957), "La entonación en el español y su morfología", Boletín de Filología, 9, Santiago de Chile, pp. 153-169.

SOSA, J. M. (1999), La entonación del español. Su estructura fónica, variabilidad y dialectología, Cátedra, Madrid.

YEN HUI, L. (2005), La entonación del español hablado por taiwaneses, Tesis doctoral, Biblioteca Phonica, 2, [on-line] http://www.publicacions. ub.edu/revistes/phonica-biblioteca/esp_taiw/esp_taiw.pdf, 18.05.2020.

ZHAO, T. S. (2019), "La entonación de las preguntas del español hablado por chinos", Phonica, 15, pp. 119-140, https://doi.org/10.13140/ RG.2.2.27250.32960. 